\title{
Malaria and HIV co-infection and their effect on haemoglobin levels from three health- care institutions in Lagos, southwest Nigeria
}

\author{
*Sanyaolu $\mathrm{AO}^{1,2,4}$, Fagbenro-Beyioku $\mathrm{AF}^{1}$, Oyibo $\mathrm{WA}^{1}$, Badaru $\mathrm{OS}^{2}$, Onyeabor $\mathrm{OS}^{3}$, Nnaemeka $\mathrm{CI}^{1}$
}

1. Department of Medical Microbiology and Parasitology, College of Medicine of the University of Lagos, Idi-araba, PMB 12003 Lagos, Nigeria

2. Central Public Health Laboratory of the Federal Ministry of Health, Yaba, Lagos, Nigeria

3. The Satcher Health Leadership Institute, Department of Community Health and Preventive Medicine, Morehouse School of Medicine, Atlanta, USA

4. Department of Medical Microbioloy and Immunology, St. James School of Medicine, Albert Lake Dr. The Quarter, P. O. Box 318, The Valley, Anguilla, BWI

\begin{abstract}
Background: Malaria and human immunodeficiency virus (HIV) are two major infections with enormous public health consequence. Together, they are endemic in many developing countries with anaemia being the most frequent haematological consequence of the infections.

Objective: To determine the prevalence of malaria and HIV co-infection as well as anaemia among selected patients from three health-care institutions in Lagos, Nigeria.

Methods: A cross-sectional study of 1080 patients was carried out to determine the prevalence of malaria and HIV coinfection as well as anaemia. Blood sera from each of the patients were screened for malaria parasites, HIV-1 and HIV-2 using Giemsa stain, Cambridge Biotech Recombigen HIV-1/HIV-2 rapid device, respectively while haemoglobin estimation was performed using cyanmethemoglobin method.

Results: Our data showed that the total number of malaria infected patients were significantly higher in HIV sero-positive patients $47.7 \%$ (31/65) when compared with their HIV sero-negative counterparts $25.8 \%(262 / 1015) \mathrm{P}=0.047$. The result also revealed that $25.8 \%(8 / 31)$ of the patients co-infected with malaria and HIV had anaemia as compared to $11.1 \%$ (29/ 262) infected with malaria alone. Multivariable logistic regression analysis showed that patients with dual infection of malaria and HIV were twice likely to be anaemic than those infected with malaria alone [adjusted OR 2.4, 95\% CI, 1.3 to 2.7, $\mathrm{P}=0.014]$.

Conclusion: Our data indicated a higher prevalence of malaria in HIV infected patients and also revealed that patients coinfected with malaria and HIV were more likely to be anaemic.

Keywords: Malaria, malaria and HIV co-infection, anaemia, parasite density

African Health Sciences 2013; 13(2): 295 - 300 http://dx.doi.org/10.4314/ahs.v13i2.14
\end{abstract}

\section{Introduction}

Malaria remains one of the leading causes of morbidity and mortality globally and nearly half of the global populations are at risk of malaria infection. Malaria and human immunodeficiency virus (HIV) infection accounted for over 3 million deaths in 2007 and millions more are adversely affected each year ${ }^{1}$. However, current report indicates a major global reduction in malaria cases between 2000 and 2010 due to control efforts ${ }^{2}$. Nigeria has the largest population in Africa with a population of over 150

*Corresponding author:
Dr. Adekunle O. Sanyaolu
Department of Medical Microbioloy and
Immunology, St. James School of Medicine, Albert
Lake Dr. The Quarter, P. O. Box 318, The Valley,
Anguilla, BWI
Email: sanyakunle@hotmail.com

African Health Sciences Vol 13 Issue 2 June 2013 million and HIV prevalence of $4.6 \%$ in $2008^{3}$. It is estimated that 2.95 million individuals live with HIV/ AIDS in Nigeria ${ }^{4}$ and integrated control efforts are immeasurably needed ${ }^{5,6}$.

The prevalence of malaria and HIV infection overlaps in most endemic regions and co-infection of these infections have important public health implications. This geographical overlap of these infections has generated global interest in terms of their potential interactions and an integrated control effort in most endemic regions is essential. While early population-based studies reported no association between malaria and HIV co-infection ${ }^{7-}$ ${ }^{9}$, recent study from east sub-Saharan Africa indicated malaria as a risk factor of concurrent HIV infection at the population level ${ }^{10}$. Malaria is believed to increase HIV replication in vitro ${ }^{11}$ and in vivo ${ }^{12}$. In 
addition, evidence shows that malaria co-infection with HIV triggers malaria disease progression, increases the risk of severe malaria in adults ${ }^{13,14}$, increases risk of congenital infection ${ }^{15}$ and this dual infection fuels the spread of both diseases especially in sub-Saharan Africa ${ }^{16}$. This compelling evidence has called for integrated health sciences for early, effective and preventive treatment of both infections ${ }^{17}$. In pregnant women, HIV infection increases the risk of high-density Plasmodium falciparum infection, higher risk of maternal anaemia and lowbirth weight ${ }^{18}$. HIV and malaria each interact with the host's immune system, and this interaction often results in a complex activation of immune cells which cause dysfunctional levels of cytokine and antibody productions ${ }^{19}$. In addition, $\mathrm{CD} 4^{+} \mathrm{T}$ cells have a major role in the development and maintenance of antimalaria immunity, but HIV infections meddle with this immunity ${ }^{20}$.

The majority of studies on malaria and HIV coinfection in sub-Saharan Africa have been from eastern and southern part of the continent.

In a cross-sectional study, we examined the prevalence of malaria and HIV co-infection as well as anaemia among selected patients from three health-care institutions in Lagos.

\section{Methods}

\section{Study design and population}

Patients from three health-care institutions in Lagos - General Hospital Ikeja, Sexually Transmitted Diseases Clinic Yaba, and the Central Public Health Laboratory Yaba - were selected for this crosssectional study between 1996 and 1997. The healthcare institutions selected for the study were as a result of their strategic functions: (a) referral centres for HIV positive and STD patients, (b) client-based facilities serving people who want to know their HIV and STD status, and (c) provider-based facilities providing specific medical services to the communities.

The study was designed with the primary interests of investigating parasitic infection among HIV infected patients. Details of the study design have been published elsewhere ${ }^{21}$. Briefly, the same blood samples from the published work on enteroparasitic infections mentioned above were used for the screening of HIV, malaria parasite and haemoglobin obtained with informed consent from 1080 patients out of 2000 patients targeted for the study. Consent could not be obtained from 920 patients who declined to participate. Those who refused to be enrolled were all given appropriate clinical services and were excluded from the study. Information on questionnaires administered on the recruited patients included age, sex, symptoms, frequency of malaria attack and any anti-malarial drug taken in the past two weeks prior to the study. Parents or guardians of younger patients assisted in filling questionnaires. Written informed consent or thumbprints were received from all recruited individuals and the study received ethical approval from the Federal Ministry of Health Authority.

\section{Laboratory procedures}

Thick and thin blood smears from each of the study individuals were made on grease-free slides and stained with Giemsa to determine species of malaria parasites and parasite density according to the earlier published protocol ${ }^{22}$. Parasite densities were estimated by counting the number of $P$. falciparum malaria parasites (parasite count) per 200 leukocytes per high power field (number of parasites/ $\mu$ l of blood $)^{23}$. All stained slides were examined by microscopy and read by two competent microscopists using 100 power fields under oil immersion. Where there were discordances, a third microscopist re-examined the slide. A definitive malaria diagnosis was determined by a reddish chromatin dot with a purple or blue cytoplasm of the malaria parasite seen together while a slide was pronounced negative when 100 high power fields have been examined using x100 oil immersion objective lens.

Haemoglobin $(\mathrm{Hb})$ estimation was performed using cyanmethemoglobin method ${ }^{24}$. Malaria anaemia was defined as haemoglobin $<11$ $\mathrm{g} / \mathrm{dL}$ in the presence of microscopically detectable asexual parasitaemia, while severe malaria anaemia was defined as $\mathrm{Hb}<5 \mathrm{~g} / \mathrm{dL}$, with $P$. falciparum parasitaemia of $>250,000$ parasites $/ \mu 1$. Blood sera of each of the patients were screened for HIV-1 and HIV-2 using the Cambridge Biotech Corporation Recombigen HIV-1/HIV-2 (Galway, Republic of Ireland) rapid test device while confirmation of positive cases was done with Immunocomb 11 (Yavne, Israel) and Biorad Novapath HIV-1 Immunoblot (Biorad, Hercules, CA, USA) for HIV-2 and HIV-1, respectively.

\section{Statistical analysis}

The obtained data were analysed using the Epi-Info statistical software version 6.0 (CDC, GA, USA) and GraphPad InStat (GraphPad Software Inc., CA, 
USA). Univariable analyses were based on Pearson's Chi-square test for comparison of proportions. Fisher's exact tests for contingency tables were used to test for significance in proportions of categorical data when the expected cell counts were less than 5 . Binary logistic regression was applied for the analysis of associations with haemoglobin which was used as the dependent variable against the explanatory variables (malaria and $\mathrm{HIV} /$ malaria co-infection) in multivariable analysis controlling for age, sex, parasite density and parasitic infections. Odds ratios (OR) with $95 \%$ confidence interval (CI) were used to measure the strength of associations. All tests were two-tailed and $P$ value $<0.05$ was considered statistically significant.

\section{Results}

Among the 1080 selected patients, 293 (27.1\%) were infected with malaria parasites and $31(2.9 \%)$ with malaria/HIV co-infection. The patients consisted of
$570(52.8 \%)$ males and $510(47.2 \%)$ females. P. falciparum and $P$. malariae were the only two types of malaria parasite species found in the blood smear of the sampled patients. Infection with $P$. falciparum $24.8 \%(268 / 1080)$ recorded the highest prevalence among the patients when compared with $P$. malariae $0.6 \%(7 / 1080)$ and $1.7 \%(18 / 1080)$ had mixed infection with both parasites (Table 1). There were no significant differences between the prevalence of P. falciparum malaria in HIV sero-positive and seronegative patients. However, the prevalence of $P$. malariae was statistically significantly higher in HIV sero-positive patients though the sample size was small. In addition, mixed malaria infection was also statistically significantly higher among HIV seropositive patients when compared with HIV seronegative patients $(6.2 \%$ versus $1.4 \%)$. The total number of malaria infected patients was significantly higher in HIV sero-positive patients (47.7\%) than the HIV sero-negative patients $(25.8 \%)$ as indicated in table 1.

Table 1: Prevalence and species of Plasmodium sp infection in relation to HIV status of the study participants

\begin{tabular}{|c|c|c|c|c|}
\hline Plasmodium sp & $\begin{array}{l}\text { Total } \\
\mathrm{n}=1080(\%)\end{array}$ & $\begin{array}{l}\text { HIV- } \\
\mathrm{n}=1015(\%)\end{array}$ & $\begin{array}{l}\text { HIV+ } \\
\mathrm{n}=65(\%)\end{array}$ & P value \\
\hline P. falciparum & $268(24.8)$ & $243(23.9)$ & $25(38.5)$ & 0.082 \\
\hline P. malariae & $7(0.6)$ & $5(0.5)$ & $2(3.1)$ & $<0.001 *$ \\
\hline Mixed infection & $18(1.7)$ & $14(1.4)$ & $4(6.2)$ & $0.017^{*}$ \\
\hline $\begin{array}{l}\text { Total no. of malaria infected } \\
\text { patients }\end{array}$ & $293(27.1)$ & $262(25.8)$ & $31(47.7)$ & 0.047 \\
\hline
\end{tabular}

exact test.

Among the respondents, analysis from the questionnaire showed that there were no major differences in the prevalence of parasitaemia with patients who reportedly used anti-malarial drugs two weeks prior to the study irrespective of their HIV status. In total, $4.2 \%(45 / 1080)$ of the recruited patients reportedly used anti-malarial treatment prior to the study and still had parasitaemia. Out of which $40 \%(18 / 45)$ were HIV sero-positive and 60\% (27/ 45) HIV sero-negative patients. Although there were no statistical significance with the categories of parasite density in relation to the patients' HIV status, the median parasite density in HIV sero-negative patients was higher than that of the HIV sero-positive patients as shown in table 2 .

Table 2: Malaria parasite density in relation to HIV status

\begin{tabular}{lccc}
\hline $\begin{array}{l}\text { Parasite } \\
\text { density } \\
\text { (No. of }\end{array}$ & \multicolumn{2}{l}{$\begin{array}{l}\text { No. of malaria infected } \\
\text { patients with }\end{array}$} & P value \\
\cline { 2 - 3 } $\begin{array}{l}\text { parasites } \\
\boldsymbol{\mu} / \mathbf{1})\end{array}$ & $\mathrm{nIV}=31(\%)$ & $\mathrm{HIV}-$ & \\
& & & \\
$0-999$ & $23(74.2)$ & $200(76.3)$ & \\
$1000-9999$ & $8(25.8)$ & $57(21.8)$ & 0.64 \\
$>10,000$ & $0(0)$ & $5(1.9)$ & \\
$\begin{array}{l}\text { Median } \\
\text { (Interquartile }\end{array}$ & 754.43 & 962.24 & 0.21 \\
range) & & & \\
\hline
\end{tabular}

Analysis from the questionnaire also indicated that there were no statistically significant differences in the frequency of malaria attack between the HIV sero-positive and HIV sero-negative patients while it tended to be higher among HIV sero-positives. 
Since anaemia is the most frequent haematological consequence of malaria and HIV infection, their association was explored. No selected patient had severe malaria anaemia during the study. Taken together, only $3.4 \%(37 / 1080)$ of the recruited patients had anaemia at the time of the study.
However, patients with malaria and HIV co-infection had higher odds of anaemia than patients with malaria alone in multivariable logistic regression analysis $(11.1 \%$ versus $25.8 \%)$, adjusted OR $2.4(95 \% \mathrm{CI}$, 1.3 to $2.7, \mathrm{P}=0.014$ ) as shown in table 3 .

Table 3: Multivariable logistic regression analysis of the risk of anaemia with malaria and HIV coinfection

\begin{tabular}{lclll}
\hline Category & $\begin{array}{c}\text { Malaria } \\
\mathbf{( n = 2 6 2 )}\end{array}$ & $\begin{array}{l}\text { Malaria/HIV } \\
\text { co-infection(n = 31) }\end{array}$ & $\begin{array}{c}\text { Adjusted } \\
\text { OR (95\% CI) }\end{array}$ & P value \\
\hline Haemoglobin $<11 \mathrm{~g} / \mathrm{dl}$ & $29(11.1)$ & $8(25.8)$ & $2.4(1.3$ to 2.7$)$ & 0.014 \\
Haemoglobine $>11 \mathrm{~g} / \mathrm{dl}$ & $233(88.9)$ & $23(74.2)$ & $0.8(0.3$ to 3.1$)$ & 0.78 \\
\hline
\end{tabular}

Adjusted for age, sex, parasite density and parasitic infections. $\mathrm{OR}=$ odds ratio, $\mathrm{CI}=$ confidence interval

\section{Discussion}

Our results underscore the higher prevalence of malaria infection in HIV sero-positive patients than HIV sero-negative patients. In addition, our data showed a $2.9 \%$ prevalence of patients co-infected with malaria and HIV. While some interactions between malaria and HIV have been studied extensively, individuals with HIV are considered to be at high risk of malaria in endemic areas ${ }^{25}$. Accumulating data have shown the effects of HIV1 infection in adults and children on malaria ${ }^{13,26}$ and also in pregnant women ${ }^{15}$. In multigravid women, HIV appeared to impair a pregnant woman's ability to control malaria parasitaemia thereby resulting in high parasite density when compared to HIV negative pregnant women ${ }^{27}$.

The trademark of malaria infection is anaemia, especially with $P$. falciparum infection. The aetiology of anaemia is usually multifactorial due to malnutrition, iron deficiency, vitamins $\mathrm{A}, \mathrm{C}$ and $\mathrm{B}_{12}$ deficiency, foliate deficiency, sickle cell anaemia, thalassemia, HIV, bothriocephaliasis, malaria and other parasites such as hookworm, Ascaris and Schistosoma ${ }^{28,29}$. However, in sub-Saharan Africa, malaria is a major contributor of anaemia ${ }^{30}$. Though it is demanding to measure all parameters in one study, our data indicated that patients infected with both malaria and HIV were more likely to have anaemia than those infected with malaria alone. Similarly, a study from Zambia showed that HIV-1 infected malaria patients had a slower haematological recovery after successful parasite clearance ${ }^{31}$. In another study, assessing haematological predictors of increased severe anaemia in Kenyan children, the authors indicated that malaria/HIV-1 co-infection was characterized by more profound anaemia and increased mortality ${ }^{32}$. In addition, patients infected with HIV have more frequent and severe episodes of malaria ${ }^{33}$.

Our data showed no differences in the prevalence of patients with parasitaemia between HIV seropositive and sero-negative patients who used antimalarial drug two weeks prior to the study. Data have shown that HIV infected individuals with low CD4 cell counts and anaemia had increased risk of anti-malarial treatment failure ${ }^{34}$. In another study, viral burden in some patients can be partly reduced with anti-malarial therapy. ${ }^{35}$ Our results indicated a higher median parasite density in HIV sero-negative patients than the HIV sero-positive patients. One would have expected the reverse due to the immunocompromised state of the HIV infected patients. One important limitation of this study is its cross-sectional nature, limiting us to a small sample size with patients co-infected with malaria and HIV. In view of this, our results should be interpreted with reference to the observed. Perhaps, a cohort study of HIV-infected patients in malarial endemic areas will reveal more information on the interaction between the two infections. Another limitation of this study is the inability to carry out a CD4 count and viral load on HIV-infected individuals due to limited resources. However, the clinical and public health implication of HIV and malaria, especially in endemic regions, is overwhelming.

\section{Conclusion}

Our data indicated a higher prevalence of malaria in HIV infected patients and also revealed that patients with malaria and HIV co-infection were more likely to have anaemia than patients with only malaria infection.

African Health Sciences Vol 13 Issue 2 June 2013 


\section{Acknowledgements}

The authors appreciate all the patients and the three health care institutions that participated in the study.

\section{References}

1. WHO. World Malaria Report 2008. WHO Press, Geneva, Switzerland. 2008.

2. WHO. World Malaria Report 2011. World Global Malaria Programme, Geneva, Switzerland 2011; http:/

/ w w w. w ho.int/malaria/ world_malaria_report_2011/ 9789241564403_eng.pdf.

3. FMOH. Nigeria Federal Ministry of Health. National HIV Sentinel Survey. A Technical Report Abuja. 2008.

4. WHO/UNAIDS/UNICEF. Epidemiological fact sheet on HIV and AIDS. Core data on epidemiology and response Nigeria 2008 update. October 2008. 1-24. (http:// apps.who.int/globalatlas/predefinedReports/ EFS2008/full/EFS2008_NG.pdf) 2008.

5. Chukwujekwu O, Chabikuli NO, Merrigan M, Awi D, Hamelmann C. Integrating reproductive health and HIV indicators into the Nigerian health system-building an evidence base for action. African Journal of Reproductive Health 2010;14:10916.

6. Merrigan M, Azeez A, Afolabi B, Chabikuli ON, Onyekwena O, Eluwa G, Aiyenigba B, Kawu I, Ogungbemi K, Hamelmann C. HIV prevalence and risk behaviours among men having sex with men in Nigeria. Sexually Transmitted Infections 2011;87:65-70.

7. Nguyen-Dinh P, Greenberg AE, Mann JM, Kabote N, Francis H, Colebunders RL, Huong AY, Quinn TC, Davachi F, Lyamba B, et al. Absence of association between Plasmodium falciparum malaria and human immunodeficiency virus infection in children in Kinshasa, Zaire. Bulletin of the World Health Organization 1987;65:607-13.

8. Fleming AF. AIDS in Africa — an update. AIDS Forsch 1988;3:116-38.

9. Salako LA, Idigbe EO, Erinosho MA, Akinosho RO, Mafe AG. Malaria and Human Immunodeficiency Virus (HIV) infection among adults in Ogun State, South-Western Nigeria. Nigerian Quarterly Journal of Hospital Medicine 1996;6:279-83.

10. Cuadros DF, Branscum AJ, Crowley PH. HIVmalaria co-infection: effects of malaria on the prevalence of HIV in East sub-Saharan Africa.
International Journal of Epidemiology 2011;40:9319.

11. Xiao LH, Owen SM, Rudolph DL, Lal RB, Lal AA. Plasmodium falciparum antigen-induced human immunodeficiency virus type 1 replication is mediated through induction of tumor necrosis factor-alpha. The Journal of Infectious Diseases 1998;177:437-45.

12. Kamya MR, Gasasira AF, Yeka A, Bakyaita N, Nsobya SL, Francis D, Rosenthal PJ, Dorsey G, Havlir D. Effect of HIV-1 infection on antimalarial treatment outcomes in Uganda: a population-based study. The Journal of Infectious Diseases 2006;193:9-15.

13. Whitworth J, Morgan D, Quigley M, Smith A, Mayanja B, Eotu H, Omoding N, Okongo M, Malamba S, Ojwiya A. Effect of HIV-1 and increasing immunosuppression on malaria parasitaemia and clinical episodes in adults in rural Uganda: a cohort study. Lancet 2000;356:1051-6.

14. French N, Nakiyingi J, Lugada E, Watera C, Whitworth JA, Gilks CF. Increasing rates of malarial fever with deteriorating immune status in HIV-1-infected Ugandan adults. AIDS 2001;15:899-906.

15. Perrault SD, Hajek J, Zhong K, Owino SO, Sichangi M, Smith G, Shi YP, Moore JM, Kain KC. Human immunodeficiency virus coinfection increases placental parasite density and transplacental malaria transmission in Western Kenya. The American Journal of Tropical Medicine and Hygiene 2009;80:119-25.

16. Abu-Raddad LJ, Patnaik P, Kublin JG. Dual infection with HIV and malaria fuels the spread of both diseases in sub-Saharan Africa. Science 2006;314:1603-6.

17. Van geertruyden JP, D'Alessandro U. Malaria and HIV: a silent alliance. Trends in Parasitology 2007;23:465-7.

18. Ned RM, Moore JM, Chaisavaneeyakorn S, Udhayakumar V. Modulation of immune responses during HIV-malaria co-infection in pregnancy. Trends in Parasitology 2005;21:284-91.

19. Hochman S, Kim K. The Impact of HIV and Malaria Coinfection: What Is Known and Suggested Venues for Further Study. Interdisciplinary Perspectives on Infectious Diseases 2009;2009:617954.

20. Troye-Blomberg M, Berzins K. Immune interactions in malaria co-infections with other endemic infectious diseases: implications for the 
development of improved disease interventions. Microbes and Infection 2008;10:948-52.

21. Sanyaolu AO, Oyibo WA, Fagbenro-Beyioku AF, Gbadegeshin AH, Iriemenam NC. Comparative study of entero-parasitic infections among HIV sero-positive and sero-negative patients in Lagos, Nigeria. Acta Tropica 2011;120:268-72

22. Agomo CO, Oyibo WA, Anorlu RI, Agomo PU. Prevalence of malaria in pregnant women in Lagos, South-West Nigeria. Korean Journal of Parasitology 2009;47:179-83.

23. Cheesbrough M. District Laboratory Practice in Tropical Countries, Part 2, 2nd edition. Cambridge University Press 2006:440 pages

24. Bhaskaram P, Balakrishna N, Radhakrishna KV, Krishnaswamy K. Validation of hemoglobin estimation using Hemocue. Indian Journal of Pediatrics 2003;70:25-8.

25. Idemyor V. Human immunodeficiency virus (HIV) and malaria interaction in sub-Saharan Africa: the collision of two Titans. HIV Clinical Trials 2007;8:246-53.

26. ter Kuile FO, Parise ME, Verhoeff FH, Udhayakumar V, Newman RD, van Eijk AM, Rogerson SJ, Steketee RW. The burden of coinfection with human immunodeficiency virus type 1 and malaria in pregnant women in subsaharan Africa. The American Journal of Tropical Medicine and Hygiene 2004;71:41-54.

27. Steketee RW, Wirima JJ, Bloland PB, Chilima B, Mermin JH, Chitsulo L, Breman JG. Impairment of a pregnant woman's acquired ability to limit Plasmodium falciparum by infection with human immunodeficiency virus type-1. The American Journal of Tropical Medicine and Hygiene 1996;55:42-9.

28. Magalhaes RJ, Clements AC. Mapping the risk of anaemia in preschool-age children: the contribution of malnutrition, malaria, and helminth infections in West Africa. PLoS Medicine 2011;8:e1000438.

29. Beales PF. Anaemia in malaria control: a practical approach. Annals of Tropical Medicine and Parasitology 1997;91:713-8.

30. Savage EJ, Msyamboza K, Gies S, D'Alessandro U, Brabin BJ. Maternal anaemia as an indicator for monitoring malaria control in pregnancy in sub-Saharan Africa. BJOG: An International Journal of Obstetrics \& Gynaecology 2007;114:1222-31.

31. Van Geertruyden JP, Mulenga M, Chalwe V, Michael N, Moerman F, Mukwamataba D, Colebunders R, D'Alessandro U. Impact of HIV-1 infection on the hematological recovery after clinical malaria. The Journal of Acquired Immune Deficiency Syndromes 2009;50:200-5.

32. Davenport GC, Ouma C, Hittner JB, Were T, Ouma Y, Ong'echa JM, Perkins DJ. Hematological predictors of increased severe anemia in Kenyan children coinfected with Plasmodium falciparum and HIV-1. American Journal of Hematology 2010;85:227-33.

33. Hochman S, Kim K. The Impact of HIV Coinfection on Cerebral Malaria Pathogenesis. Journal of Neuroparasitology 2012;3:235547.

34. Shah SN, Smith EE, Obonyo CO, Kain KC, Bloland PB, Slutsker L, Hamel MJ. HIV immunosuppression and antimalarial efficacy: sulfadoxine-pyrimethamine for the treatment of uncomplicated malaria in HIV-infected adults in Siaya, Kenya. The Journal of Infectious Diseases 2006;194:1519-28.

35. Hoffman IF, Jere CS, Taylor TE, Munthali P, Dyer JR, Wirima JJ, Rogerson SJ, Kumwenda N, Eron JJ, Fiscus SA, Chakraborty H, Taha TE, Cohen MS, Molyneux ME. The effect of Plasmodium falciparum malaria on HIV-1 RNA blood plasma concentration. AIDS 1999;13:487-94. 